\title{
マルチウェイ・スピーカのドップラ歪補償
}

\section{Doppler Distortion Compensation for Multi-way Speakers}

○米谷 昭彦 (名工大)

Akihiko Yoneya, Nagoya Institute of Technology, Gokiso-cho, Showa-ku, Nagoya

Key Words : Doppler Distortion, System Inversion, Multi-way Speaker

1.はじめに

オーディオシステムにおいてスピーカは電気信号を音 圧に変換する重要な役割を担っているが、その動作原理か らドップラ効果により相互変調歪（以下、ドップラ歪と記 す）が発生してしまう[1]。このドップラ歪が音質に与え る影響については報告がないが、本報告ではドップラ歪を 補償する方法について提案する。ドップラ歪は時間遅れの 時間変化として現れるタイプの非線形歪であり、多ウェイ スピーカを単一アンプにより駆動する場合には、複数の時 変時間遅れを含む非線形性を補償する必要がある。そこで、 system inversion [2]の考え方を用いてこの多ウェイスピ 一カに対するドップラ歪を補償するアプローチを用いた。

\section{2. 多ウェイスピーカのドップラ歪}

ここでは 2 ウェイスピーカを例にとり、そのドップラ歪 について説明する。対象とするスピーカシステムの概略を Fig. 1 に示す。

いま、ウーハーおよびツイータの変位を $p_{w}(t)$ および $p_{t}(t)$ 、微小信号における観測者までの音圧特性を

$$
S_{w}(s)=G_{w}(s) U(s)
$$

および

$$
S_{t}(s)=G_{t}(s) U(s)
$$

とする。ただし、 $U(s)$ はアンプの出力電圧 $u(t)$ のラプラ ス変換であり、 $S_{w}(s)$ および $S_{t}(s)$ はそれぞれウーハーお よびツイータによりもたらされる音圧である。このとき、 微小ではない信号に対する観測者が観測する音圧は

$$
s_{o}(t)=s_{w}\left(t-\frac{p_{w}(t)}{c}\right)+s_{t}\left(t-\frac{p_{t}(t)}{c}\right)
$$

となる。ただし $c$ は音速である。また $G_{w}(s)$ および $G_{t}(s)$ に も固定時間の無駄時間要素を含んでいる。

ここで問題となるのが、スピーカの変位によって変化す る無駄時間の影響であり、本稿ではこの入力信号によって 変動する無駄時間の影響を補償する手法を提案する。

\section{System inversion による補償}

System inversion はシステムの非干渉化器や非線形補 償器の設計などに用いられる手法であり、本稿では離散時 間システムに対して system inversion を適用することに より、複数の変動無駄時間となって現れる多ウェイスピー カにおけるドップラ歪補償を行う。本節では本報告で用い る離散時間系における system inversion の概略について 説明する。

いま、一入出力の補償の対象が $\boldsymbol{x}[k+1]=A[k] \boldsymbol{x}[k]+\boldsymbol{b}[k] u[k]$

$$
y[k]=c[k] x[k]
$$

と表されており、

$$
c[k+1] b[k]>0
$$

が常に成り立つものとする。ただし、 $\boldsymbol{A}[k], \boldsymbol{b}[k], c[k]$ は $x[k]$ および $u[k]$ に依存する場合もある。このとき、

$$
\begin{gathered}
x[k+1]=A[k] \boldsymbol{x}[k]+\boldsymbol{b}[k] v[k] \\
y[k]=c[k] \boldsymbol{x}[k] \\
y[k] \equiv u[k-1]
\end{gathered}
$$

となるような $v[k]$ を生成する問題を考える。 この問題に対しては、

$$
v[k]=(c[k] b[k-1])^{-1}(u[k]-c[k] \boldsymbol{A}[k-1] x[k-1])
$$

とすることで解が得られることは簡単な計算で得られる。 ただし、この補償器を含んだシステムが安定である必要が ある。線形時不変系の場合は、補償の対象が不安定零点を 持っていなければ安定となることは知られているが、非線 形系や時変系の場合には注意が必要となる。

\section{4. ドップラ歪補償への適用}

本節では、前節で述べた補償手法をドップラ歪補償に適 用する方法について考える。ここで、音源信号 $u[k]$ は PCM 信号で与えられ、補償器出力信号 $v[k]$ も PCM 信号である とする。

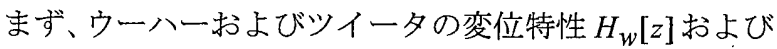
$H_{t}[z]$ を予め測定しておく。すなわち、

$$
\begin{aligned}
& P_{w}[z]=H_{w}[z] V[z] \\
& P_{t}[z]=H_{t}[z] V[z]
\end{aligned}
$$

により、ウーハーおよびツイータのコーンの変位の離散時 間信号である $p_{w}[k]$ および $p_{t}[k]$ が推定できるようにして おく。

次に、ウーハーおよびツイータの音圧特性 $G_{w}(s)$ および $G_{t}(s)$ に対して、その振幅特性を表現する最小位相特性を 持つ峳密にプロパーな伝達関数 $G_{w}^{m}(s)$ および $G_{t}^{m}(s)$ を測 定し、実現しておく。

$$
\begin{aligned}
& G_{w}^{m}(s)=\boldsymbol{c}_{w}^{c}\left(s \boldsymbol{I}-\boldsymbol{A}_{w}^{c}\right)^{-1} \boldsymbol{b}_{w}^{c} \\
& \left|G_{w}^{m}(j \omega)\right|=\left|G_{w}(j \omega)\right|, \forall \omega \\
& G_{t}^{m}(s)=\boldsymbol{c}_{t}^{c}\left(s \boldsymbol{I}-\boldsymbol{A}_{t}^{c}\right)^{-1} \boldsymbol{b}_{t}^{c} \\
& \left|G_{t}^{m}(j \omega)\right|=\left|G_{t}(j \omega)\right|, \forall \omega
\end{aligned}
$$

ドップラ歪補償を行う際、無駄時間補償をすることにな るが、正の無駄時間を補償することはできないので、音圧 特性 $G_{w}(s)$ および $G_{t}(s)$ に対して予め時間 $\tau-\frac{p_{w}(t)}{c}$ およ び $\tau-\frac{p_{t}(t)}{c}$ だけ無駄時間を持たせたシステムを考える。す なわち、

$$
\begin{aligned}
& \dot{\boldsymbol{x}}_{w}(t)=A_{w}^{c} \boldsymbol{x}_{w}(t)+\boldsymbol{b}_{w}^{c} v(t) \\
& y_{w}(t)=c_{w}^{c} \boldsymbol{x}_{w}\left(t-\tau+\frac{p_{w}(t)}{c}\right)
\end{aligned}
$$




$$
\begin{aligned}
& \dot{x}_{t}(t)=A_{t}^{c} \boldsymbol{x}_{t}(t)+\boldsymbol{b}_{t}^{c} v(t) \\
& y_{t}(t)=c_{t}^{c} x_{t}\left(t-\tau+\frac{p_{t}(t)}{c}\right)
\end{aligned}
$$

とする。ただし、信号 $v[k]$ のサンプリング周期 $T$ に対し $\tau 0<\tau-\frac{p_{w}(t)}{c}<T, 0<\tau-\frac{p_{t}(t)}{c}<T$ が成り立つように $\tau$ の值を設定する。そして、上記のシステムを零次ホールド を用いて離散時間化する。ウーハーについては

$$
\begin{aligned}
& \boldsymbol{x}_{w}[k+1]=\boldsymbol{A}_{w} \boldsymbol{x}_{w}[k]+\boldsymbol{b}_{w} v[k] \\
& y_{w}[k]=c_{w}\left(p_{w}[k]\right) \boldsymbol{x}_{w}[k]+d_{w}\left(p_{w}[k]\right) v[k-1] \\
& \boldsymbol{A}_{w}=\exp \left\{\boldsymbol{A}_{w}^{c} T\right\}, \boldsymbol{b}_{w}=\int_{0}^{T} \exp \left\{\boldsymbol{A}_{w}^{c} t\right\} d t \boldsymbol{b}_{w}^{c}, \\
& c_{w}\left(p_{w}[k]\right)=c_{w}^{c} \exp \left\{\boldsymbol{A}_{w}^{c}\left(\tau-p_{w}[k]\right)\right\} \\
& d_{w}\left(p_{w}[k]\right)=c_{w}^{c} \int_{0}^{\tau-p_{w}[k]} \exp \left\{A_{w}^{c} t\right\} d t \boldsymbol{b}_{w}^{c} \\
& \text { ツイータについても同様に } \\
& \boldsymbol{x}_{t}[k+1]=\boldsymbol{A}_{t} \boldsymbol{x}_{t}[k]+\boldsymbol{b}_{t} v[k] \\
& y_{t}[k]=c_{t}\left(p_{t}[k]\right) x_{t}[k]+d_{t}\left(p_{t}[k]\right) v[k-1] \\
& \boldsymbol{A}_{t}=\exp \left\{\boldsymbol{A}_{t}^{c} T\right\}, \boldsymbol{b}_{t}=\int_{0}^{T} \exp \left\{\boldsymbol{A}_{t}^{c} t\right\} d t \boldsymbol{b}_{t}^{c}, \\
& c_{t}\left(p_{t}[k]\right)=c_{t}^{c} \exp \left\{\boldsymbol{A}_{t}^{c}\left(\tau-p_{t}[k]\right)\right\} \\
& d_{t}\left(p_{t}[k]\right)=c_{t}^{c} \int_{0}^{\tau-p_{t}[k]} \exp \left\{\boldsymbol{A}_{t}^{c} t\right\} d t \boldsymbol{b}_{t}^{c} \\
& y[k]=y_{w}[k]+y_{t}[k] \\
& =c_{w}\left(p_{w}[k]\right) x_{w}[k]+c_{t}\left(p_{t}[k]\right) x_{t}[k] \\
& +\left\{d_{w}\left(p_{w}[k]\right)+d_{t}\left(p_{t}[k]\right)\right\} v[k-1]
\end{aligned}
$$

に対して一定の無駄時間が掛かったものとなる。ここで、 ドップラ歪を補償するためには、 $y[k]=u[k-1]$ とすればよ いので、これを実現するためには

$$
\begin{aligned}
v[k]= & \left\{d_{w}\left(p_{w}[k]\right)+d_{t}\left(p_{t}[k]\right)\right\}^{-1} \\
& \left\{u[k]-c_{w}\left(p_{w}[k]\right) x_{w}[k]-c_{t}\left(p_{t}[k]\right) x_{t}[k]\right\}
\end{aligned}
$$

とすればよいことがわかる。ただし、補償器を含んだシス テムの安定性には留意する必要がある。

\section{5. 適用例}

提案するドップラ歪補償をクリプトン社の 2 ウェイス ピーカ KX-3P に対して適用してみた。スピーカの変位特 性をモデル化したものを Fig. 2 に示す。ウーハーに関し ては 3 次でモデル化し、ツイータについては 4 次でモデル 化した。これらのモデルにはネットワークの特性も含んで いる。

また、このスピーカに対して音圧特性を測定し、それを モデル化したものを Fig. 3 に示す。この特性をもとに $G_{w}^{m}(s)$ および $G_{t}^{m}(s)$ を決めた。サンプリング周期は $T=1 / 44100$ [s] とし、 $\tau=0.8 T$ とした。 $c_{w}\left(p_{w}[k]\right)$ ， $d_{w}\left(p_{w}[k]\right), c_{t}\left(p_{t}[k]\right)$ および $d_{t}\left(p_{t}[k]\right)$ を逐次厳密に計算 することは効率的ではないので、 $p_{w}[k]$ および $p_{t}[k]$ に対 して $[0.7 T, 0.9 T]$ 範囲で 3 次の多項式近似を行い評価し た。ドップラ歪のみの検出は困難であったが、試聴により
その効果を確認することができた。

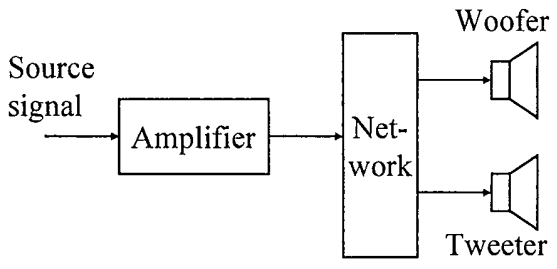

Fig. 1: Structure of speaker system.

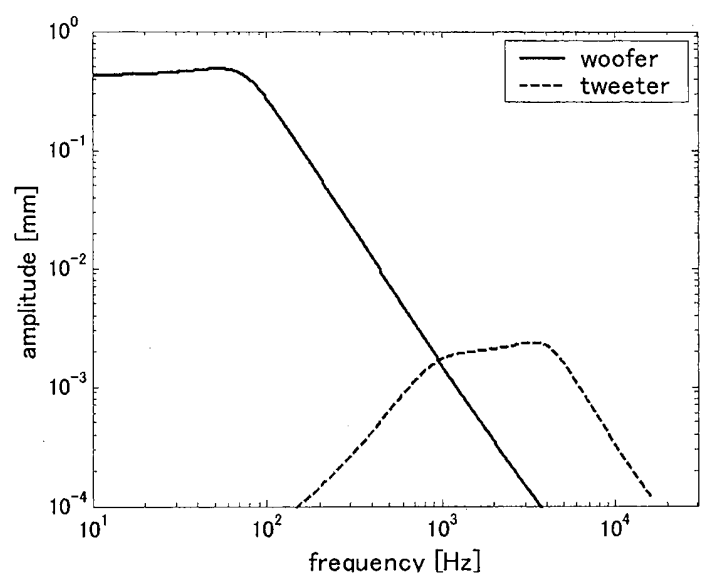

Fig. 2: Modeled cone deviation amplitude characteristics of the speakers at a driving voltage of $4 \mathrm{~V}_{\mathrm{amp}}$.

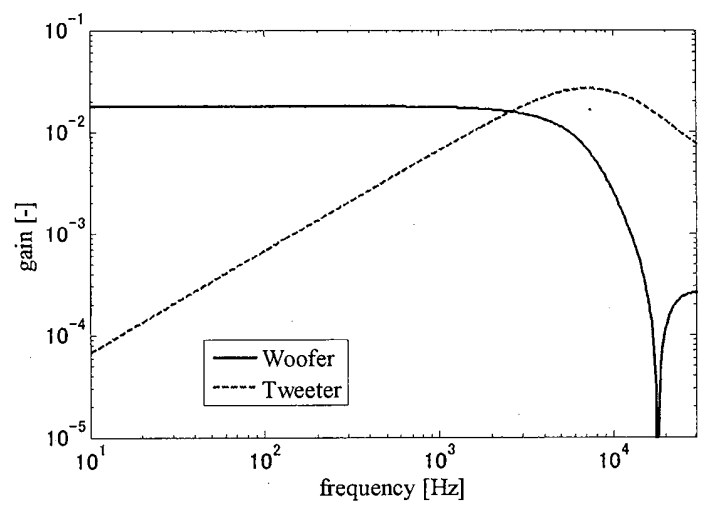

Fig. 3: Modeled frequency characteristics of the speakers.

Table 1: Specifications of the speaker (KX-3P).

\begin{tabular}{ll}
\hline type & two-way \\
rating input power & $50[\mathrm{~W}]$ \\
cross-over frequency & $2500[\mathrm{~Hz}]$ \\
dimension & $350 \times 219 \times 290[\mathrm{~mm}]$ \\
\hline
\end{tabular}

参考文献

[1] Butterweck, H.J., "About Doppler nonlinearities in loudspeakers," 1989 IEEE International Conference on Acoustics, Speech, and Signal Processing, vol.3, pp. 2061 2063, 1989

[2] Freund, E., "The structure of decoupled nonlinear systems," Int. J. Contr., 21, 3, pp. 443-450 (1975) 